\title{
Haemodynamics after Mustard's operation for transposition of the great arteries ${ }^{1}$
}

\author{
Eric D. Silove ${ }^{2}$ and James F. N. Taylor \\ From Department of Clinical Physiology and The Thoracic Unit, The Hospital for Sick Children, Great \\ Ormond Street, London
}

Cardiac catheterization data from 54 investigations after Mustard's procedure were examined to study the influence of the operation on pressure events in the atria, great veins, and pulmonary circulation. Systemic venous atrial pressure tracings were characterized by a rapid, sharp ' $y$ ' descent. Pressure gradients between the venae cavae and systemic venous atrium were invariable, whether or not vena caval pathway obstruction was present, the ' $y$ ' trough and ' $a$ ' wave gradients being greater than the mean gradient. Pulmonary venous atrial pressure tracings were not different from normal except when tricuspid regurgitation was present. It is suggested that the baffle effectively reduces the size and compliance of the systemic venous atrium, but influences the pulmonary venous atrium to a lesser degree.

The systolic pressure gradient from the left ventricle to pulmonary artery was decreased postoperatively, suggesting that it may be flow-related; the greatest changes were seen in the group with preoperative ventricular septal defect. The ratio of pulmonary : systemic vascular resistance did not change significantly after operation, and it is suggested that both the pre-and postoperative values were higher than normal. Examination of the left ventricular or pulmonary arterial mean pressure postoperatively should raise the suspicion of a complication, e.g. pulmonary venous obstruction or tricuspid regurgitation.

Since 1964, the physiological correction of transposition of the great arteries has been achieved by Mustard's operation in numerous patients. Several reports of postoperative studies have included both immediate and long-term results (Kidd and Mustard, 1966; Shankar et al., 1967: Price et al., 1971; Stark et al., 1972; Rodrigues-Fernandez et al., 1972; Morgan et al., 1972; Rizk, Moller, and Amplatz, 1973; Newfeld et al., 1974; Venables, Ediz, and Clarke, 1974; Stark et al., 1974).

In Mustard's procedure an artificial baffle channels vena caval blood through the mitral valve into the left ventricle, and pulmonary venous blood through the tricuspid valve into the right ventricle. The present report considers the influence of the baffle on the pressure events in the atria and great veins, and the changes in the pulmonary vascular and left ventricular dynamics.

The importance of recognizing postoperative Received 25 March 1976.

${ }^{1}$ This work was supported in part by a grant from the British Heart Foundation.

2Present address: Department of Paediatric Cardiology, The Children's Hospital, Birmingham. vena caval pathway obstruction has previously been stressed (Stark et al., 1974). An examination of venous and atrial pressure events is fundamental to the understanding of this complication. Pulmonary vascular disease is well documented as an early complication of transposition of the great arteries (Ferguson, Adams and Watson, 1960; Noonan et al., 1960; Ferencz, 1966; Viles, Ongley, and Titus, 1969; Mair et al., 1971; Newfeld et al., 1974). The importance of evaluating the pulmonary vascular resistance preoperatively has been stressed (Mair et al., 1971; Newfeld et al., 1974). An objective assessment of the postoperative pulmonary vascular dynamics is, therefore, relevant in determining the influence of preoperative values on the long-term result.

\section{Subjects and methods}

Forty-eight of the 256 survivors of Mustard's operation performed between 1965 and 1974 have been studied by cardiac catheterization, 6 of them on 2 occasions. The age at operation ranged from 3 months to 20 years (median 28 months) and at re- 
investigation from 5 months to 25 years (median 47 months). The interval between the operation and the investigation ranged from 1 week to 6 years (mean 21 months, median 13 months). In all instances, there were clinical indications for cardiac catheterization. Some patients were investigated because they presented with the physical signs of vena caval pathway obstruction, of pulmonary venous obstruction, or of severe tricuspid regurgitation. Others were studied because one of these complications was suspected, because they were cyanosed, or

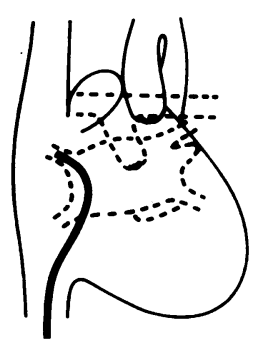

a

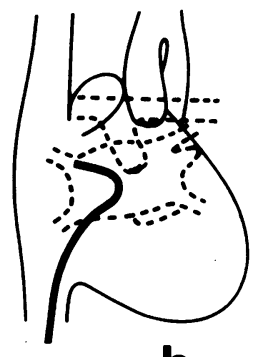

b
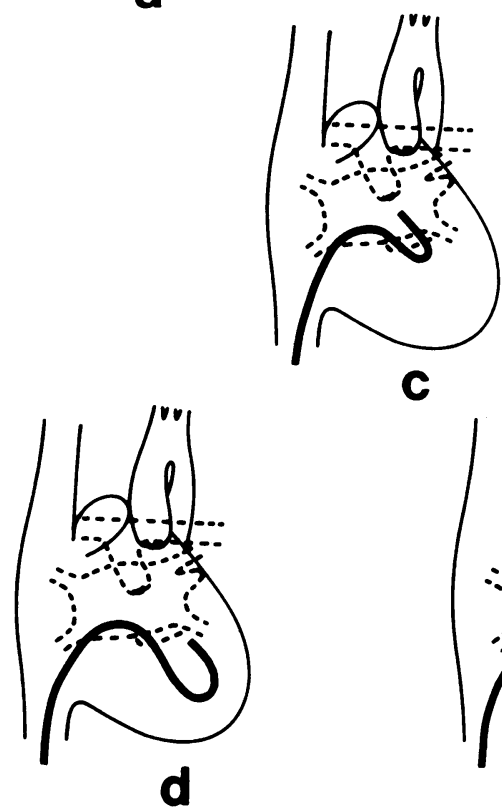

C

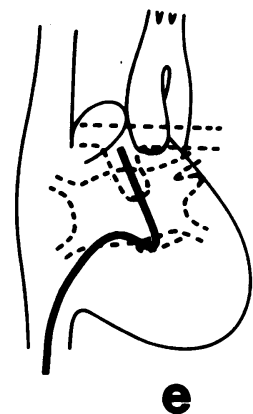

FIG. 1 Catheterization of the pulmonary artery in transposition of the great arteries using a Goodale Lubin catheter. The catheter tip is positioned in the right upper pulmonary vein (a) and a loop formed (b). This loop is passed through the mitral valve (c) into the left ventricle and positioned so that the tip remains cranially directed, and the loop laterally directed $(d)$. If the catheter is then withdrawn, the tip will pass into the pulmonary artery $(e)$. because there was cardiac enlargement, usually with a loud systolic murmur.

Both the systemic and pulmonary venous sides of the heart were catheterized in 35 of the 54 studies but only the systemic venous side in the remaining 19. The systemic venous catheter was introduced via a convenient vein in either the upper or lower limb, and the systemic venous atrium and ventricle were entered easily from either the superior or inferior vena cava. It was usually easy to enter the pulmonary artery with a standard Lehman or Cournand catheter. Difficulties in manipulating the catheter through the systemic venous atrium post-

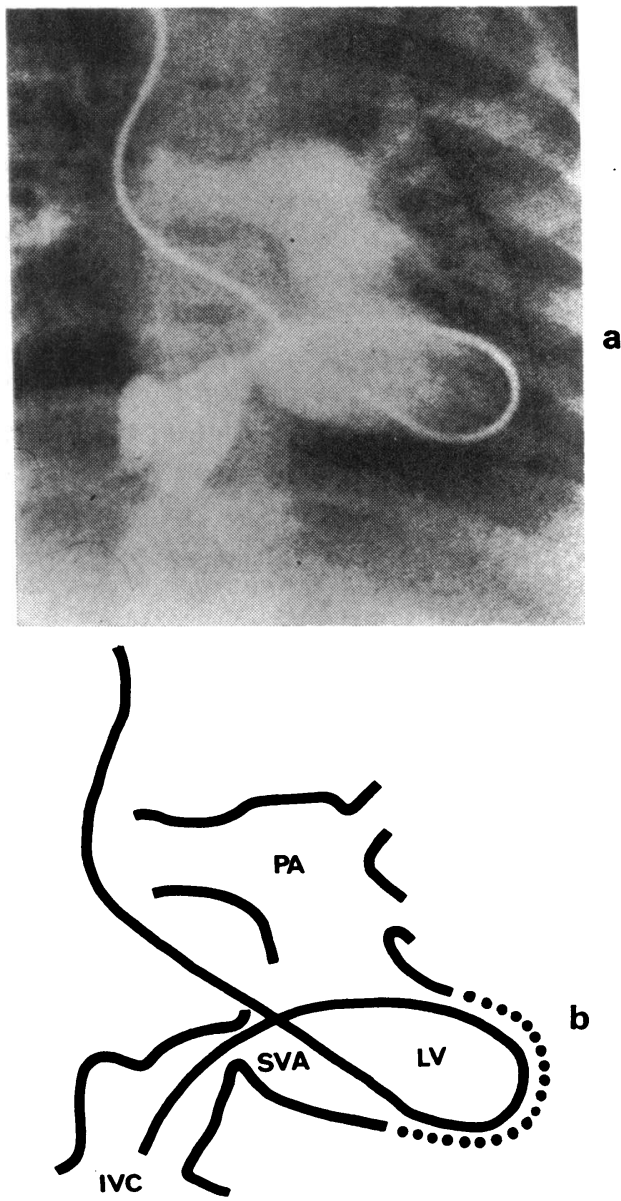

FIG. 2 (a) Technique for catheterizing inferior vena cava (IVC) from superior vena cava (SVC) after Mustard's operation (see text). The loop of the catheter lies in the left ventricle ( $L V)$ and the tip has re-emerged from the mitral valve into systemic venous atrium (SVA) and inferior vena cava. There is some intracardiac inferior vena caval pathway obstruction. (b) Line drawing of Fig. 2 (a). 
operatively, and into the pulmonary artery preoperatively and postoperatively, were overcome by techniques illustrated in Fig. 1 and 2. The pulmonary venous atrium and most of the pulmonary veins were entered retrogradely from the aorta and right ventricle without difficulty.

In most instances, pressure and oxygen saturation were measured in the heart chambers, great arteries, and great veins. Pressures were measured with a fluid-filled catheter using Statham P23 Gb pressure transducers and a Mingograph 81 Recorder. Selective angiocardiography was performed as indicated (Stark et al., 1972; Tynan, Aberdeen, and Stark, 1972; Stark et al., 1974). The relevant findings from preoperative cardiac catheterization studies were available for comparison in almost all the patients who were restudied postoperatively.

With respect to the pulmonary vascular and left ventricular dynamics we have compared the following variables:

(1) Pulmonary arterial mean pressure $\left(\mathrm{P}_{\overline{\mathrm{PA}}}\right)$.

(2) Left ventricular peak systolic pressure.

(3) Peak systolic pressure gradient between the left ventricle $\left(P_{L V}\right)$ and pulmonary artery $\left(P_{P A}\right)$. This was expressed as: (a) the absolute gradient and (b) the gradient in relation to flow ratio; thus, the postoperative gradient was compared with the preoperative index of:

$$
\frac{\mathbf{P}_{\mathbf{L V}}-\mathbf{P}_{\mathbf{P A}}}{\dot{\mathbf{Q}}_{\mathrm{p}} / \dot{\mathbf{Q}}_{\mathrm{s}}}
$$

where $\dot{Q}_{\mathrm{p}} / \dot{Q}_{\mathrm{s}}$ is pulmonary: systemic flow ratio derived from blood oxygen saturation data.

(4) Ratio of pulmonary: systemic vascular resistance $\left(\mathbf{R}_{\mathrm{p}} / \mathbf{R}_{\mathrm{s}}\right)$. The preoperative ratio was calculated using the formula:

$$
\mathbf{R}_{p} / \mathbf{R}_{\mathbf{s}}=\frac{\dot{Q}_{s}\left(P_{\overline{\mathrm{PA}}}-P_{\overline{L A}}\right)}{\mathbf{Q}_{p}\left(P_{\overline{A O}}-P_{\overline{R A}}\right)}
$$

where $P_{\overline{P A}}, P_{\overline{L A}}, P_{\overline{A O}}$, and $P_{\overline{R A}}$ represent mean pressures in pulmonary artery, left atrium, aorta, and right atrium, respectively. The postoperative ratio was calculated in the same way except that the pulmonary venous atrial mean pressure was substituted for $P_{\overline{L A}}$ and the average of the vena caval mean pressures for $P_{\overline{R A}}$. $Q_{p} / Q_{s}$ was assumed to be unity in the absence of shunts, and for the purpose of these calculations, coronary sinus flow into the pulmonary venous atrium was ignored.

The above variables were analysed in the group as a whole and in subgroups with the following:

(a) Preoperative ventricular septal defect.

(b) Postoperative systemic venous pathway obstruction (Stark et al., 1974). (c) Postoperative tricuspid regurgitation (Tynan et al., 1972).

(d) 'Simple' transposition of the great arteries with no postoperative complications. Preoperative and postoperative values of each variable were compared using the paired ' $t$ ' test.

\section{Results}

(a) Superior and inferior vena caval and systemic venous atrial pressure

The systemic venous atrial pressure tracings had the usual waves and troughs but were characterized by a rapid, sharp ' $y$ ' descent coinciding with early ventricular diastole (Fig. 3, 4, 5). In 44 of the 54 cardiac catheterizations ' $a$ ' and ' $v$ ' waves and ' $x$ ' and ' $y$ ' troughs were identifiable; the ' $y$ ' trough was lower than the ' $x$ ' in all but two cases, the mean difference in pressures being $4 \mathrm{mmHg}(0.5 \mathrm{kPa})$

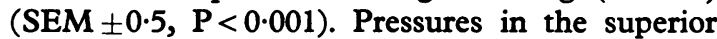
and inferior vena cava were generally higher than in the systemic venous atrium whether or not the vena caval pathways were obstructed clinically (Table 1). This was true of the mean pressures and of the individual pressure waves and troughs. In both the obstructed and unobstructed groups the 'a' wave and ' $y$ ' trough gradients were significantly greater than the mean gradients (Table 1, Fig. 3, 4, 5).

As expected, the pressure gradients were usually greater when obstruction was present. Giant ' $a$ ' waves were seen in some superior vena caval pressure tracings (Fig. 3). In these cases, cineangiography showed intracardiac obstruction of the superior vena caval pathway and presystolic reflux of contrast material up the superior vena cava, which was attributed to contraction of the right atrial appendage, upstream to the obstruction.

\section{(b) Pulmonary venous atrial pressures}

After Mustard's operation, the pulmonary venous atrium drains through the tricuspid valve into the right ventricle. Thus, the tricuspid valve has the same physiological function as the mitral valve in the normal circulation. The pulmonary venous atrial mean pressures did not differentiate between those patients who had grade 1 and 2 tricuspid regurgitation and those who did not ('Normals') (Table 2). The ' $v$ ' waves were significantly higher in the group with tricuspid regurgitation. In the 'Normals' there was no significant difference between the magnitudes of the ' $a$ ' and ' $v$ ' waves or between the ' $x$ ' and ' $y$ ' troughs. In patients with tricuspid regurgitation the ' $v$ ' waves were significantly higher than the ' $a$ ' (mean difference $8.6 \mathrm{mmHg}(1.1 \mathrm{kPa}), \mathrm{P}<0.01)$ and the ' $y$ ' troughs were significantly lower than the 


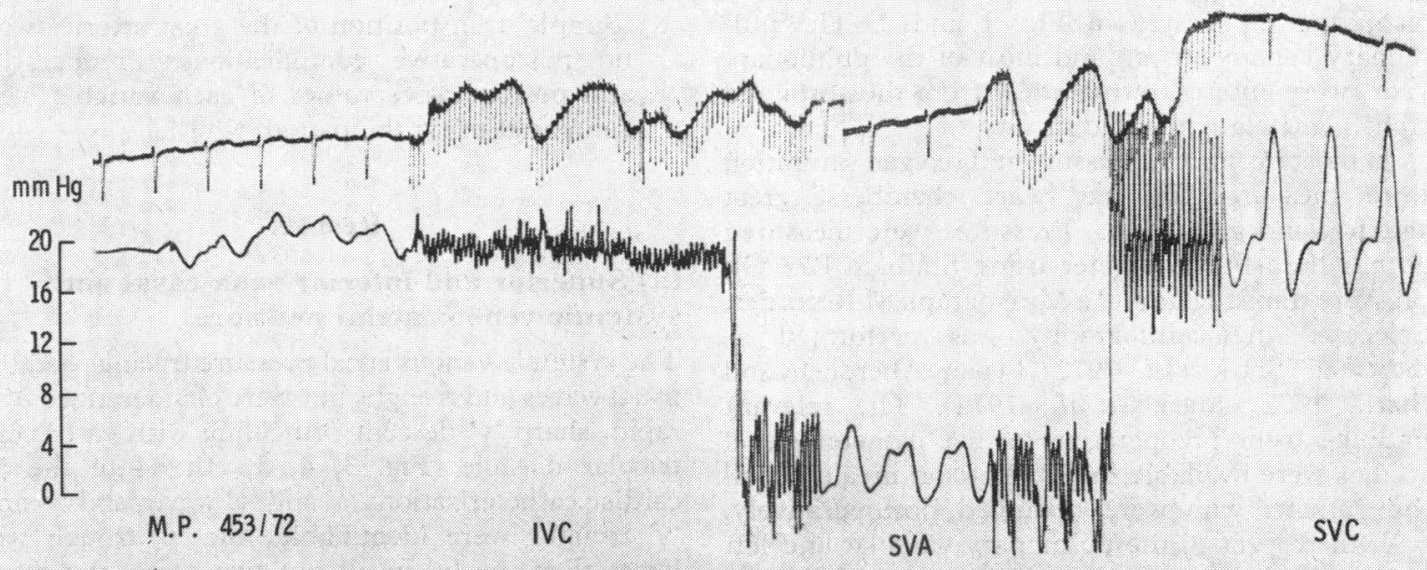

FIG. 3 Withdrawal pressure tracing from inferior vena cava through systemic venous atrium (SVA) to superior vena cava (SVC) in patient with obstruction of both vena caval pathways. Note giant ' $a$ ' waves in superior vena caval (SVC) tracing and deep ' $y$ ' troughs in systemic venous atrium ( $S V A)$.

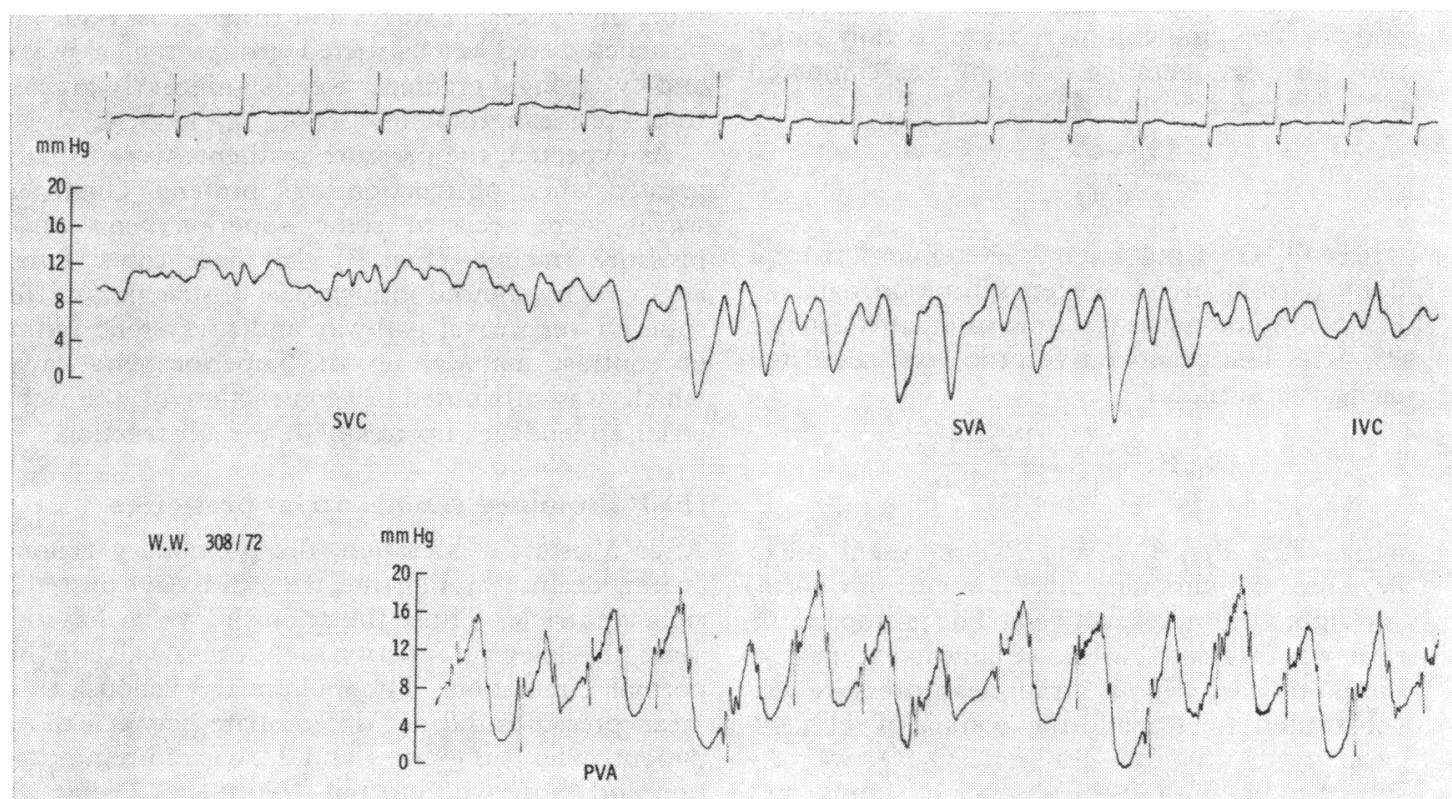

FIG. 4 Simultaneous recording of pulmonary venous atrial (PVA) pressure and pressure during withdrawal from superior vena cava (SVC) through systemic venous atrium (SVA) to inferior vena cava (IVC). Patient has mild tricuspid regurgitation with dominant ' $v$ ' waves in pulmonary venous atrium. Note small pressure gradients from both superior vena cava and inferior vena cava to systemic venous atrium despite absence of clinical or angiographic evidence of vena caval pathway obstruction. Note also the dominant ' $y$ ' trough in systemic venous atrium but not in superior or inferior vena cava. 


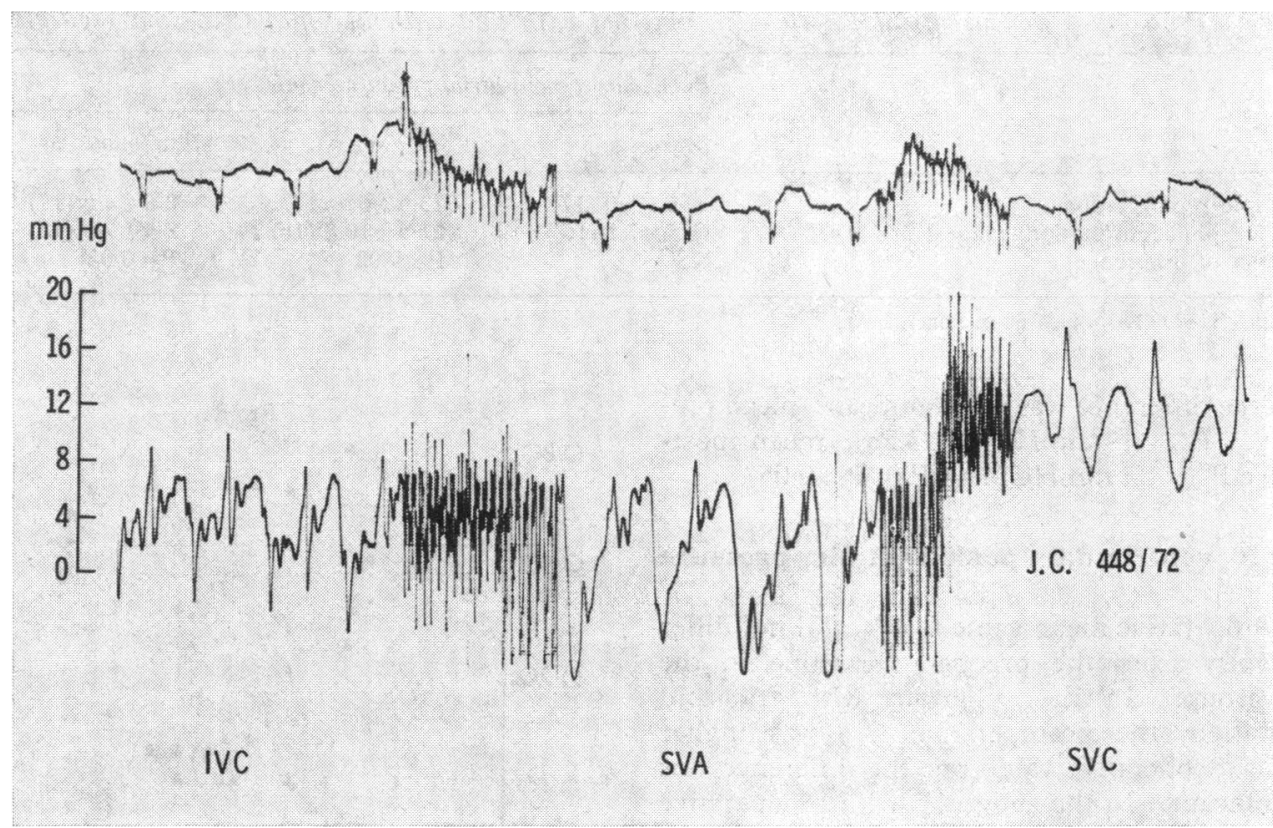

FIG. 5 Withdrawal pressure tracing from inferior vena cava (IVC) through systemic venous atrium ( $S V A$ ) to superior vena cava (SVC) in patient with superior vena caval pathway obstruction. Note ' $y$ ' trough in systemic venous atrium, absence of significant gradient between inferior vena cava and systemic venous atrium, and high superior vena cava pressure.

' $x$ ' (mean difference $4.5 \mathrm{mmHg}(0.6 \mathrm{kPa}), \mathrm{P}<0.001)$ (Fig. 4). Thus in patients with tricuspid regurgitation the ' $v$ ' wave was the highest and the ' $y$ ' trough was the lowest in the pulmonary venous atrial pressure tracing. In 4 patients with severe tricuspid regurgitation, mean pulmonary venous atrial pressures were raised to a mean of $28 \mathrm{mmHg}(3 \cdot 7 \mathrm{kPa})$ (Tynan et al., 1972).

Two of the patients in this study had pulmonary venous obstruction with mean pressure gradients of 10 and $30 \mathrm{mmHg}(1.3$ and $4.0 \mathrm{kPa})$ between the pulmonary veins and pulmonary venous atrium
(Stark et al., 1972). In all other patients with pulmonary venous pressure measurements, gradients were not present.

(c) Pulmonary arterial mean pressure $\left(\mathbf{P}_{\overline{P A}}\right)$ Postoperative values for $P_{\overline{P A}}$ did not differ significantly from preoperative values in the whole group or in the subgroups with preoperative ventricular septal defect or postoperative systemic venous pathway obstruction. In the subgroup with moderate to severe tricuspid regurgitation, the postoperative $P_{\overline{P A}}$ tended to be higher than the preoperative

TABLE 1 Pressure gradients between venae cavae and systemic venous atrium (SVA)

\begin{tabular}{llll}
\hline & \multicolumn{2}{l}{ Pressure gradient $(\mathrm{mmHg})^{\star}$} & \\
\cline { 2 - 4 } & Unobstructed & SVC obstructed & IVC obstructed \\
\hline SVC_SVA mean & $3 \cdot 9 \pm 1 \cdot 8(29)$ & $16 \cdot 9 \pm 9 \cdot 0 \star \star \star(19)$ & \\
SVC_SVA 'a' wave & $3 \cdot 1 \pm 4 \cdot 6(26)$ & $20 \cdot 3 \pm 10 \cdot 0 \star \star \star(16)$ & \\
SVC-SVA 'y' trough & $6 \cdot 6 \pm 3 \cdot 1(28)$ & $19 \cdot 0 \pm 8 \cdot 9 \star \star \star(18)$ & $17 \cdot 8 \pm 8 \cdot 8 \star \star \star(5)$ \\
IVC-SVA mean & $1 \cdot 3 \pm 1 \cdot 7(23)$ & $5 \cdot 4 \pm 4 \cdot 4 \star \star(14)$ & $20 \cdot 6 \pm 8 \cdot 9 \star \star \star(5)$ \\
IVC-SVA 'y' trough & $3 \cdot 7 \pm 2 \cdot 9(2)$ & $7 \cdot 6 \pm 5 \cdot 3 \star \star(14)$ & \\
\hline
\end{tabular}

*Average gradient $\pm 1 \mathrm{SD}$. No. of cases in parentheses.

Significance of differences between gradients in obstructed and unobstructed cases:

$\star \star \mathbf{P}<0.01$.

$\star \star \star \mathrm{P}<0.001$. 
TABLE 2 Pulmonary venous atrial pressures in patients with and without 'mild' tricuspid regurgitation

\begin{tabular}{llll}
\hline & \multicolumn{4}{c}{ Pulmonary venous atrial pressure (mmHg) * } \\
\cline { 2 - 4 } & Mean & ' $v$ ' wave & ' $v$ ' minus ' $a$ ' \\
\hline No tricuspid regurgitation & $9 \cdot 5 \pm 5 \cdot 0(17)$ & $13 \cdot 5 \pm 6.4(17)$ & $2 \cdot 0 \pm 4 \cdot 6(17)$ \\
'Mild' tricuspid regurgitation (grade 1 or $2 / 4)$ & $11 \cdot 5 \pm 7 \cdot 1(16)$ & $21 \cdot 5 \pm 10 \cdot 8(16)$ & $8.6 \pm 7.5(12)$ \\
Significance of difference & $\mathrm{NS}$ & $\mathrm{P}<0.02$ & $\mathrm{P}<0.02$
\end{tabular}

*Average \pm 1 SD. No. of cases in parentheses.

though the difference was not significant (mean preoperative $P_{\overline{P A}}=19 \mathrm{mmHg}(2.5 \mathrm{kPa})$, mean postoperative $\left.\mathrm{P}_{\overline{\mathrm{PA}}}=33 \mathrm{mmHg}(4.4 \mathrm{kPa}), \mathrm{P}>0.05\right)$.

\section{(d) Left ventricular peak systolic pressure} ( $\left.\mathbf{P}_{\text {Lv }}\right)$

The postoperative mean value for $P_{L V}$ did not differ significantly from the preoperative value in the whole group. In the subgroup with tricuspid regurgitation, the postoperative $P_{\mathrm{Lv}}$ was higher than the preoperative value but the difference was not significant. In the subgroup with preoperative

\section{LV-PA SYSTOLIC GRADIENT $\left(\mathrm{mm} \mathrm{Hg}^{\mathrm{m}}\right)$}

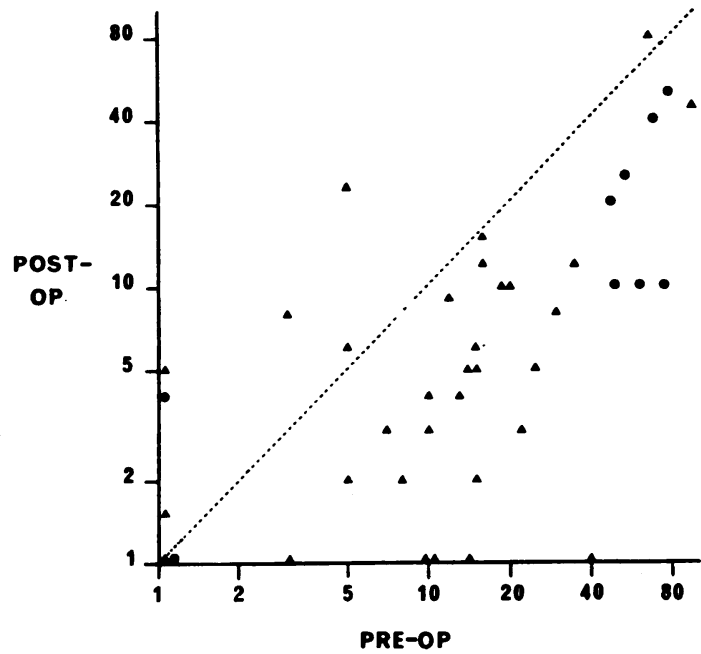

FIG. 6 Systolic pressure gradient between left ventricle and pulmonary artery before and after Mustard's operation. For convenience of display, a logarithmic scale has been used in both axes. The solid triangles represent patients with 'simple' transposition of great arteries and the solid circles represent those with ventricular septal defects. The dotted line (line of identity) shows that in the majority of patients, the preoperative gradient was greater than the postoperative.

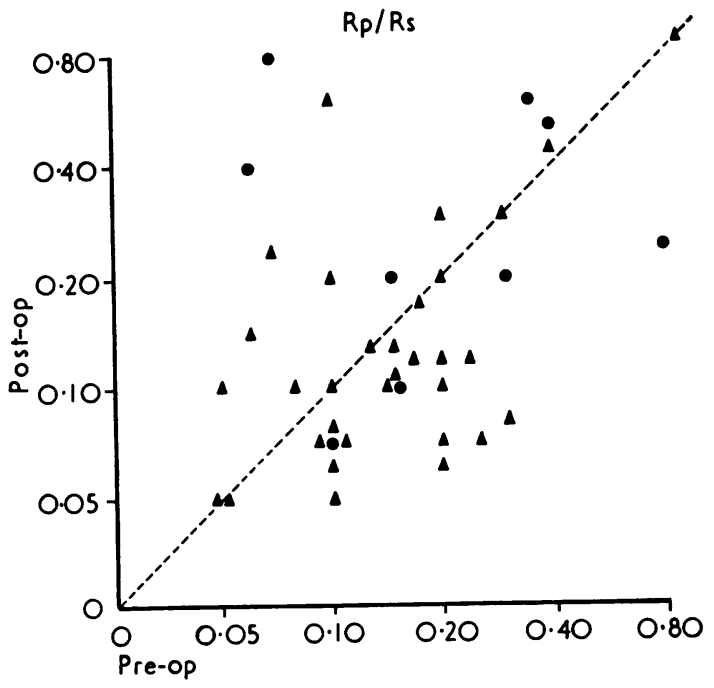

FIG. 7 The ratio of the pulmonary to systemic vascular resistance ( $R p / R s)$ was similar before and after Mustard's operation. Solid triangles represent patients who had 'simple' transposition of great arteries and the solid circles those with ventricular septal defects.

ventricular septal defect, the $P_{L v}$ decreased postoperatively by a mean of $10 \mathrm{mmHg}$ (Table 3 ). This was not significant.

(e) Peak systolic pressure gradient from left ventricle to pulmonary artery

(i) $\mathbf{P}_{\mathrm{IV}} \mathbf{P}_{\mathrm{PA}}$ was significantly smaller postoperatively in all subgroups $(P<0.01)$. The greatest change noted was in the subgroup with preoperative ventricular septal defect; the mean gradient preoperatively was $43 \mathrm{mmHg}(5.7 \mathrm{kPa})$, and postoperatively, $17 \mathrm{mmHg}(2.3 \mathrm{kPa})(\mathrm{P}<$ 0.01 ) (Fig. 6).

(ii) When $P_{L V}-P_{P A}$ was related to $Q_{p} / Q_{s}$, there was no significant difference between pre- and postoperative values in the whole group, but the subgroup with preoperative ventricular septal 
defect tended to have lower gradient/flow indices postoperatively $(P>0.05)$ (Table 3$)$. It should be noted that in this subgroup there was a high incidence of postoperative complications (Table 3) which may have influenced some of the values.

(a)

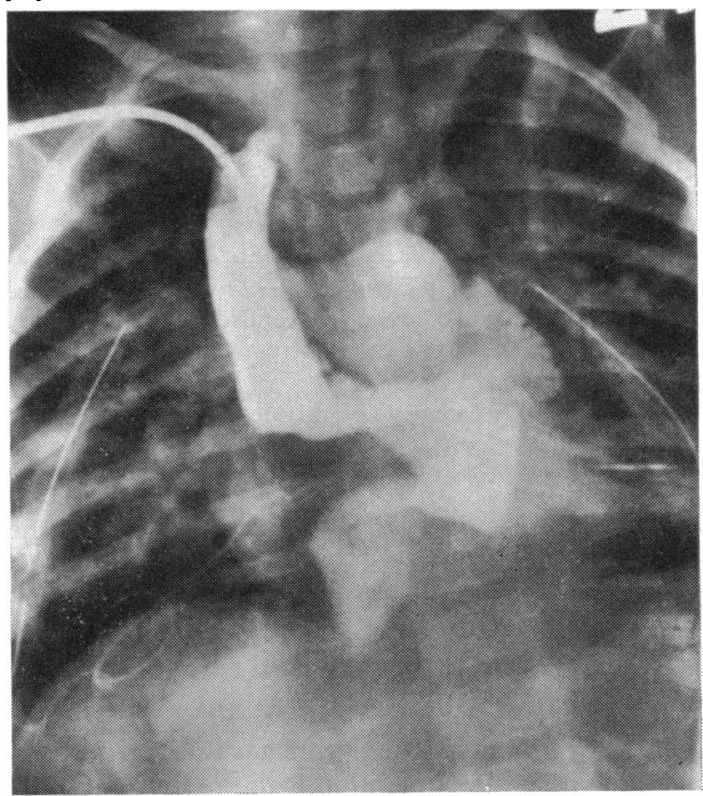

(b)

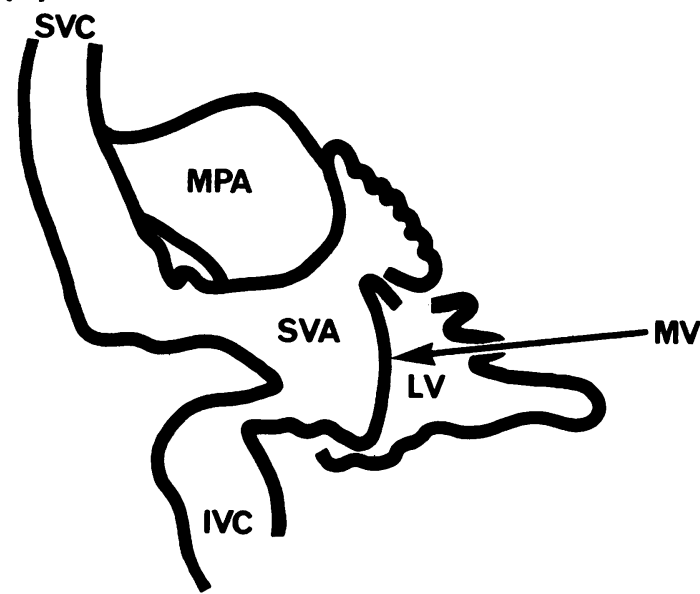

FIG. 8 (a) Superior vena caval angiogram showing the superior and inferior vena caval pathways into the newly created systemic venous atrium (previously left atrium). Note potentially small size of systemic venous atrium if intracardiac pathways of superior and inferior vena cava become narrowed. (b) Line drawing of angiogram.

\section{(f) $\mathbf{R p} / \mathbf{R s}$}

The mean value for $R_{p} / R_{s}$ in the whole group was 0.20 both before and after Mustard's operation. There was no significant difference between preand postoperative values in any of the subgroups, i.e. preoperative ventricular septal defect, postoperative tricuspid regurgitation, postoperative systemic venous pathway obstruction, and the uncomplicated cases. Some individuals who had preoperative ventricular septal defects and postoperative tricuspid regurgitation showed large changes in either direction (Table 3, Fig. 7).

\section{Discussion}

In Mustard's operation a baffle artificially redivides the atria. Its anatomical position reduces the size of the systemic venous atrium, part of which becomes incorporated into the superior and inferior vena caval pathways. Thus the baffle effectively extends the venae cavae, which in turn enter a relatively small atrial chamber above the mitral valve (Fig. 8). This may explain the characteristic changes in the wave form of the atrial pressure trazes. The most striking feature is the steep and rapid descent to the ' $y$ ' trough, coinciding with the rapid filling phase of early ventricular diastole, and thus possibly influenced by altered ventricular function. These studies do not indicate any change in left ventricular function, but a rapid ' $y$ ' descent is also seen in constrictive pericarditis, and the congestive cardiomyopathies (Wood, 1961) where atrial compliance is also reduced. In cardiac constriction, however, the ' $x$ ' and ' $y$ ' troughs are usually of similar depth whereas after Mustard's operation the ' $x$ ' trough is often barely recognizable. This supports the suggestion that after atrial contraction ('a' wave), the return of venous blood (' $v$ ' wave) into a small, relatively non-compliant chamber diminishes the fall of pressure (' $x$ ' trough) which usually follows the ' $a$ ' wave. The mechanical properties of the systemic venous atrium may also be influenced by the pericardial or 'dacron' baffle itself. Either of these materials may thicken and become relatively rigid, unlike atrial tissues, thereby altering the compliance of the atria. The reduced atrial size and compliance may together account for the observed changes in pressure wave-form.

The systemic venous atrial and superior vena caval pressure tracings described by Venables et al. (1974) are similar to those we have found. We agree that the ' $y$ ' trough gradient is probably the most sensitive indicator of some obstruction to flow from the venae cavae into the systemic venous atrium. It is conceivable that intracardiac vena caval path- 
TABLE 3 Pre-and postoperative findings in patients with ventricular septal defect

\begin{tabular}{|c|c|c|c|c|c|c|c|c|c|c|c|}
\hline $\begin{array}{l}\text { Case } \\
\text { No. }\end{array}$ & $\underset{\text { Pre }}{\dot{Q}_{p}^{\prime} \dot{Q}_{s}}$ & $\begin{array}{l}P_{\mathrm{LV}} \\
\text { Pre }\end{array}$ & Post & $\begin{array}{l}\text { PिĀ } \\
\text { Pré }\end{array}$ & Post & $\begin{array}{l}R_{p} / R s \\
\text { Pre }\end{array}$ & Post & $\begin{array}{l}P_{\mathrm{LV}}-P_{\mathrm{PA}} \\
\text { Pre }\end{array}$ & $\frac{P_{\mathrm{LV}}-P_{\mathrm{PA}}}{\underset{P_{e}}{\left(\dot{Q}_{p}\left(\dot{Q}_{s}\right)\right.}}$ & $\underset{\text { Post }}{P_{\mathrm{LV}}-P_{\mathrm{PA}}}$ & $\begin{array}{l}\text { Postoperative } \\
\text { complications }\end{array}$ \\
\hline $\begin{array}{r}1 \\
2 \\
3 \\
4 \\
5 \\
6 \\
7 \\
8 \\
9 \\
10\end{array}$ & $\begin{array}{l}1.5 \\
1.0 \\
1.5 \\
1.0 \\
1.6 \\
1.25 \\
2.6 \\
1.0 \\
3.0 \\
0.6\end{array}$ & $\begin{array}{r}100 \\
100 \\
45 \\
70 \\
100 \\
80 \\
80 \\
24 \\
120 \\
95\end{array}$ & $\begin{array}{r}130 \\
105 \\
35 \\
22 \\
80 \\
45 \\
110 \\
22 \\
60 \\
100\end{array}$ & $\begin{array}{l}16 \\
36 \\
35 \\
14 \\
43 \\
62 \\
15 \\
18 \\
45 \\
11\end{array}$ & $\begin{array}{r}70 \\
60 \\
20 \\
7 \\
50 \\
34 \\
55 \\
12 \\
30 \\
30\end{array}$ & $\begin{array}{l}0.07 \\
0.40 \\
0.30 \\
0.10 \\
0.35 \\
0.80 \\
0.06 \\
0.15 \\
0.15 \\
0.10\end{array}$ & $\begin{array}{l}0.80 \\
0.50 \\
0.20 \\
0.07 \\
0.60 \\
0.24 \\
0.40 \\
0.10 \\
0.20 \\
0.20\end{array}$ & $\begin{array}{r}76 \\
55 \\
0 \\
50 \\
48 \\
0 \\
60 \\
0 \\
62 \\
80\end{array}$ & $\begin{array}{r}51 \\
55 \\
0 \\
50 \\
30 \\
0 \\
23 \\
0 \\
21 \\
133\end{array}$ & $\begin{array}{r}10 \\
25 \\
0 \\
10 \\
20 \\
0 \\
40 \\
4 \\
10 \\
50\end{array}$ & $\begin{array}{l}\text { TR } \\
\text { TR } \\
\text { VSD, TR } \\
\text { SVO } \\
\text { VSD } \\
\text { TR, VSD } \\
\text { TR, VSD } \\
\text { SVO }\end{array}$ \\
\hline
\end{tabular}

$\dot{Q}_{\mathrm{p}} / \dot{Q}_{\mathrm{s}}=$ Pulmonary: systemic flow ratio; $\mathrm{P}_{\mathrm{LV}}=$ Left ventricular systolic pressure; $\mathbf{R}_{\mathrm{p}} / \mathbf{R}_{\mathrm{s}}=$ Pulmonary: systemic resistance ratio; $P_{\mathbf{P A}}=$ Pulmonary arterial mean pressure; $P_{L V}-P_{P_{A}}=$ Systolic pressure gradient between left ventricle and pulmonary artery.

Pre and Post refer to preoperative and postoperative measurements, respectively.

TR, tricuspid regurgitation; VSD, ventricular septal defect; SVO, systemic venous pathway obstruction.

way obstruction exaggerates the smallness of the systemic venous atrium and so contributes to the mechanics of the ' $y$ ' trough suggested above. Venables et al. (1974) have emphasized that some degree of superior vena caval pathway obstruction may be present in most patients who have had Mustard's operation. Our pressure data from a selected group of patients support this contention, but our clinical and angiographic observations (Stark et al., 1974) suggest that small pressure gradients may be of little importance

The pulmonary venous atrial pressure tracings were somewhat different from the systemic venous atrial pressures. Since the pulmonary veins enter directly into the pulmonary venous atrium, the geometry of which is not altered as radically as the systemic venous atrium, pressure gradients between the pulmonary veins and pulmonary venous atrium were rare. Only two of the patients had pulmonary venous obstruction resulting from contraction of the baffle around the orifices of the pulmonary veins (previously reported by Stark et al., 1972). When tricuspid regurgitation was present, the ' $v$ ' wave was dominant and the ' $y$ ' trough tended to be lower than the ' $x$ '. However, when there was no tricuspid regurgitation, the ' $a$ ' and ' $v$ ' waves were of similar height and the ' $x$ ' and ' $y$ ' troughs of similar depth.

Thus, the pulmonary venous atrial and systemic venous atrial dynamics were not affected in the same way by Mustard's operation. The baffle does not appear to reduce the size of the pulmonary venous atrium because it does not channel the pulmonary venous blood. The normal pressure differential between the pulmonary venous atrium and systemic venous atrium may also be a factor influencing the relative sizes of the atrial chamber after Mustard's operation. The baffle is more likely to encroach upon the systemic venous atrium and vena caval pathways than to reduce the size of the pulmonary venous atrium.

A change of practical significance occurring as a result of Mustard's operation is the reduction in the pressure gradient between the left ventricle and the pulmonary artery. A reduction of pulmonary blood flow after operation may have accounted for the decreased pressure gradient. Some support for this suggestion is found in the similarity of the pre- and postoperative gradient/flow indices which we calculated. However, it must be recognized that the $\dot{Q}_{p} / \dot{Q}_{\text {s }}$ ratio is not necessarily related to the magnitude of the pulmonary blood flow.

In patients with transposition of the great arteries, pulmonary blood flow values lie within the normal range during the first few days of life and then increase (Keane et al., 1973). This phenomenon may partly explain Tynan's (1972) observation that left ventricular outflow pressure gradients were less than $5 \mathrm{mmHg}(0.7 \mathrm{kPa})$ in the first two weeks of life, but subsequently became larger. He also showed that the pulmonary arterial pressure had decreased, but found no correlation between the pressure gradient and flow ratio. However, Keane et al. (1973) published data in graphic form which suggested some relation between the gradient and measured pulmonary blood flow, but which did not reach statistical significance.

It appears that in most cases the magnitude of 
the left ventricular outflow gradient in transposition of the great arteries is influenced by pulmonary blood flow rather than by a fixed obstruction in the outflow pathway, which frequently occurs at subvalvar leval (Tynan et al., 1969; Silove and Taylor, 1973). The diagnosis of left ventricular outflow tract obstruction requires not only the demonstration of a pressure gradient in the absence of a high flow, but also angiographic confirmation (Silove and Taylor, 1973). This is important because severe fixed stenosis may increase the difficulties of operative management (Breckenridge et al., 1972). Pulmonary vascular disease is an important complication of transposition of the great arteries and frequently presents in infancy (Ferguson et al., 1960: Noonan et al., 1960; Ferencz, 1966; Viles et al., 1969; Newfeld et al., 1974). The influence of Mustard's operation on the pulmonary vascular resistance $\left(\mathbf{R}_{\mathrm{p}}\right)$ is not well understood. Morgan et al. (1972) had 3 patients with high postoperative $R_{p}$ but preoperative values were not available for comparison. Newfeld et al. (1974) described 2 patients whose pulmonary vascular disease progressed after Mustard's operation, both on haemodynamic and biopsy evidence. In the present series, we did not have absolute values for pulmonary blood flow and could not calculate pulmonary vascular resistance. Values for $\mathbf{R}_{\mathrm{p}} / \mathbf{R}_{\mathrm{s}}$ do not necessarily reflect the dynamics of the pulmonary vascular bed. Acknowledging this limitation, the mean value for $\mathbf{R}_{\mathrm{p}} / \mathbf{R}_{\mathrm{s}}$ both before and after Mustard's operation was $0 \cdot 20$, somewhat higher than might be expected in normal subjects of comparable age. Though the operation does not appear to have significantly influenced average $R_{p} / R_{s}$ in the group as a whole, some individuals exhibited large changes in either direction. It was of interest that in 3 of 9 patients whose $R_{p} / R_{s}$ values were 0.25 or more preoperatively, the values decreased to below 0.25 after operation. On the other hand, in 3 patients whose preoperative $R_{p} / R_{s}$ values were 0.10 or less, the postoperative values rose to $0.40,0.60$, and 0.80 , respectively. These 6 patients were equally divided between the subgroups with preoperative ventricular septal defect, postoperative systemic venous pathway obstruction, and tricuspid regurgitation.

A comparison of preoperative and postoperative values for $P_{\overline{P A}}$ did not contribute significantly to the understanding of the pulmonary circulatory changes. $\mathrm{P}_{\overline{\mathrm{PA}}}$ was more usefully examired in relation to other pressures and flows to cerive $R_{p} / R_{s}$. However, it appears that the finding of a raised $P_{\overline{P A}}$ postoperatively should lead to investigation for possibly pulmonary venous obstruction or tricuspid regurgitation.

\section{References}

Breckenridge, I. M., Oelert, H., Stark, J., Graham, G. R., Bonham-Carter, R. E., and Waterston, D. J. (1972). Mustard's operation for transposition of the great arteries. Review of 200 cases. Lancet, 1, 1140.

Ferencz, C. (1966). Transposition of the great vessels. Pathophysiologic considerations based upon a study of the lungs. Circulation, 33, 232.

Ferguson, D. J., Adams, P., and Watson, D. (1960). Pulmonary arteriosclerosis in transposition of the great vessels. American fournal of Diseases of Children, 99, 653.

Keane, J. F., Ellison, R. C., Rudd, M., and Nadas, A. S. (1973). Pulmonary blood flow and left ventricular volumes in transposition of the great arteries and intact ventricular septum. British Heart fournal, 35, 521.

Kidd, L., and Mustard, W. T. (1966). Hemodynamic effects of a totally corrective procedure in transposition of the great vessels. Circulation, 33-34, Suppl. I, 28.

Mair, D. D., Ritter, D. G., Ongley, P. A., and Helmholz, H. F. (1971). Hemodynamics and evaluation for surgery of patients with complete transposition of the great arteries and ventricular septal defect. American fournal of Cardio$\log y, 28,632$.

Morgan, J. R., Miller, B. L., Daicoff, G. R., and Andrews, E. J. (1972). Hemodynamic and angiocardiographic evaluation after Mustard procedure for transposition of the great arteries. Fournal of Thoracic and Cardiovascular Surgery, 64, 878.

Newfeld, E. A., Paul, M. H., Muster, A. J., and Idriss, F. S. (1974). Pulmonary vascular disease in complete transposition of the great arteries. A study of 200 patients. American Fournal of Cardiology, 34, 75.

Noonan, J. A., Nadas, A. S., Rudolph, A. M., and Harris, G. B. C. (1960). Transposition of the great arteries (concluded). A correlation of clinical, physiologic and autopsy data. New England fournal of Medicine, 263, 739.

Price, J. E., Isabel, J., Mulder, D. G., and Gyepes, M. T. (1971). The radiographic diagnosis of complications of the Mustard procedure. American fournal of Roentgenology, Radium Therapy and Nuclear Medicine, 112, 52.

Rizk, G., Moller, J. H., and Amplatz, K. (1973). The angiographic appearance of the heart following the Mustard procedure. Radiology, 106, 269.

Rodriguez-Fernandez, H. L., Kelly, D. T., Collado, A., Haller, J. A., Krovetz, L. J., and Rowe, R. D. (1972). Hemodynamic data and angiographic findings after Mustard repair for complete transposition of the great arteries. Circulaticn, 46, 799.

Shankar, K. R., Lauer, R. M., Diehl, A. M., and Reed, W. A. (1967). Transposition of the great vessels. Hemodynamic changes after physiologic total correction. American fournal of Surgery, 114, 760.

Silove, E. D., and Taylor, J. F. N. (1973). Angiographic and anatomical features of subvalvar left ventricular outflow obstruction in transposition of the great arteries. The possible role of the anterior mitral valve leaflet. Paediatric Radiology, 1, 87.

Stark, J., Tynan, M. J., Ashcraft, K. W., Aberdeen, E., and Waterston, D. J. (1972). Obstruction of pulmonary veins and superior vena cava after the Mustard operation for transposition of the great arteries. Circulation, 45-46, Suppl. I, 116.

Stark, J., Silove, E. D., Taylor, J. F. N., and Graham, G. R. (1974). Obstruction to systemic venous return following the Mustard operation for transposition of the great arteries. Fournal of Thoracic and Cardiovascular Surgery, 68, 742.

Tynan, M. (1972). Transposition of the great arteries. Changes in the circulation after birth. Circulation, 46, 809. 
Tynan, M., Aberdeen, E., and Stark, J. (1972). Tricuspid incompetence after the Mustard operation for transposition of the great arteries. Circulation, 45-46, Suppl. I, 111.

Tynan, M., Carr, I., Graham, G., and Bonham-Carter, R. E. (1969). Subvalvar pulmonary obstruction complicating the postoperative course of balloon atrial septostomy in transposition of the great arteries. Circulation, 39-40, Suppl. I, 1-223.

Venables, A. W., Ediz, B., and Clarke, C. P. (1974). Vena caval obstruction complicating the Mustard operation for complete transposition of the great arteries. European fournal of Cardiology, 1, 401.
Viles, P. H., Ongley, P. A., and Titus, J. L. (1969). The spectrum of pulmonary vascular disease in transposition of the great arteries. Circulation, 40, 31 .

Wood, P. (1961). Chronic constrictive pericarditis. American fournal of Cardiology, 7, 48.

Requests for reprints to Dr. J. F. N. Taylor, The Thoracic Unit, The Hospital for Sick Children, Great Ormond Street, London WC1N 3JH. 